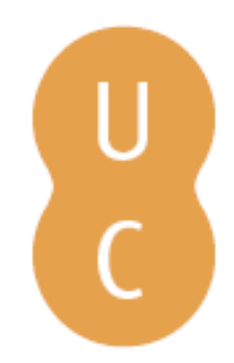

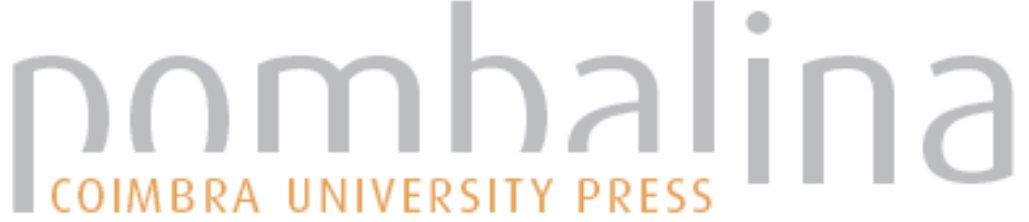

\section{Anotações sobre o futuro do multilateralismo}

Autor(es): $\quad$ Fonseca Jr., Gelson

Publicado por: Imprensa da Universidade de Coimbra

URL

persistente: URI:http://hdl.handle.net/10316.2/43159

DOI: $\quad$ DOl:https://doi.org/10.14195/978-989-26-1433-5_4

Accessed : $\quad$ 26-Apr-2023 16:23:15

A navegação consulta e descarregamento dos títulos inseridos nas Bibliotecas Digitais UC Digitalis, UC Pombalina e UC Impactum, pressupõem a aceitação plena e sem reservas dos Termos e Condições de Uso destas Bibliotecas Digitais, disponíveis em https://digitalis.uc.pt/pt-pt/termos.

Conforme exposto nos referidos Termos e Condições de Uso, o descarregamento de títulos de acesso restrito requer uma licença válida de autorização devendo o utilizador aceder ao(s) documento(s) a partir de um endereço de IP da instituição detentora da supramencionada licença.

Ao utilizador é apenas permitido o descarregamento para uso pessoal, pelo que o emprego do(s) título(s) descarregado(s) para outro fim, designadamente comercial, carece de autorização do respetivo autor ou editor da obra.

Na medida em que todas as obras da UC Digitalis se encontram protegidas pelo Código do Direito de Autor e Direitos Conexos e demais legislação aplicável, toda a cópia, parcial ou total, deste documento, nos casos em que é legalmente admitida, deverá conter ou fazer-se acompanhar por este aviso.

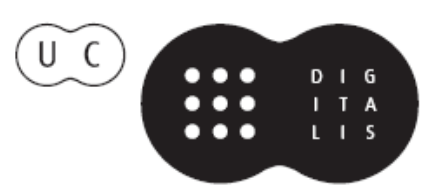




\section{Euro-Atlântico:}

\section{Espaço de Diálogos}

Isabel Maria Freitas Valente

Iranilson Buriti de Oliveira

(Coord)

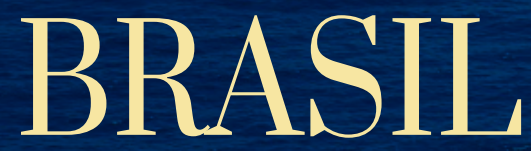

NAS ONDAS

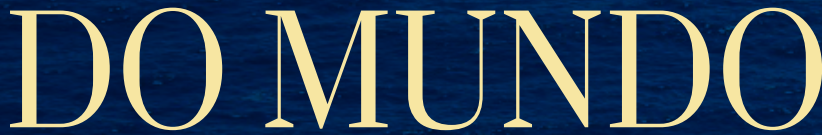

Álvaro Vasconcelos (Org)

Editora da Universidade Federal de Campina Grande

Imprensa da Universidade de Coimbra

2017 


\section{ANOTAÇÕES SOBRE O FUTURO DO MULTILATERALISMO}

Gelson Fonseca Jr., PhD Diplomata de carreira aposentado E-mail: gelson.fonseca@gmail.com

\section{Resumo}

O artigo parte de uma visão sumária das características do multilateralismo e como evoluiu em tempos recentes. Analisa os momentos de otimismo em relação ao futuro do multilateralismo quando da assinatura da Carta da ONU e do fim da Guerra Fria. Procura explicar os motivos de frustração diante da falta de efetividade das instituições multilaterais e as dificuldades para superá-las. Analisa a relação entre os cenários de evolução da distribuição de poder e o multilateralismo. Termina com uma nota sobre a vocação multilateral do Brasil e as alternativas estratégicas que terá para exercê-la.

Palavras-chave: Multilateralismo; Multipolaridade; ONU; Vocação multilateral do Brasil 


\begin{abstract}
The article starts with a summary of the characteristics of multilateralism and how it has evolved in recent times, focusing on the moments of optimism regarding its future when the Charter of the United Nations was signed and the Cold War ended. Optimism is followed nowadays by a deep sense of frustration derived from the lack of effectiveness of the multilateral institutions and the expansion of the nationalist ideologies. The difficulties to overcome the shortcomings are examined in the framework of the scenarios for the evolution of the distribution of power in the international system. A note on Brazil's alternative strategies to exert its multilateral vocation closes the article.
\end{abstract}

Keywords: Multilateralism; Multipolarity; United Nations; Brazil's Multilateral Vocation

A reflexão sobre o futuro do multilateralismo deve lembrar inicialmente que as instituições governamentais multilaterais (IGMs) são inúmeras e de objetivos variados. ${ }^{48}$ Algumas estão voltadas para as questões de segurança e da paz, como a ONU; outras dedicam-se a temas mais estritos e técnicos, como a União Postal Universal; há organizações universais e regionais; varia a natureza dos constrangimentos que aceitam os seus membros, que serão altos no caso da União Europeia e mínimos no caso da CPLP. Cada qual, em função de suas características, terá diferentes perspectivas de evolução. Assim, é possível dizer que não existe "um futuro" para o multilateralismo, mas tantos futuros quantas seriam as instituições multilaterais. ${ }^{49}$

A multiplicidade das instituições governamentais multilaterais não impede, contudo, que se formule uma perspectiva geral sobre o multila-

\footnotetext{
${ }^{48}$ Este texto corresponde, com modificações e atualizações, a apresentação feita pelo autor em seminário organizado pelo IRI-USP em abril de 2014.

${ }^{49}$ Segundo o Yearbook of International Organizations, havia, em 2003, cerca de 5000 organizações governamentais multilaterais.
} 
teralismo. Para tanto, seria necessário deixar em pano-de-fundo as instituições singulares e considerar aspectos gerais do sistema internacional, na suposição de que há modelos de ordem que favorecem a disposição para cooperar e, portanto, sustentar e fortalecer o multilateralismo, e outros que, ao estimular conflitos e dificultar decisões coletivas, levam ao enfraquecimento das IGMs. Esses movimentos se revelam mais imediatamente nas instituições que lidam com as questões de segurança. Assim, o sucesso ou fracasso do multilateralismo tende a se identificar com a capacidade de resolver conflitos internacionais, assegurar a paz, que foram os objetivos centrais das IGMs modernas, a começar com o Pacto da Liga das Nações e, depois, com a ONU. Embora não exclusivamente, nessa temática se concentra esta reflexão.

Para compreender a relação entre sistemas de poder e efeitos sobre o multilateralismo, vale lembrar que as IGMs nascem em resposta a necessidades e interesses dos Estados que as criam. ${ }^{50}$ Em certas circunstâncias, os Estados escolhem estabelecer mecanismos permanentes de cooperação, que definem a essência do multilateralismo. Em alguns casos, as motivações são claras, como no caso da necessidade de garantir a circulação internacional da correspondência postal, as rotas aéreas ou a distribuição de rádio frequência. Sem cooperação, traduzida em arranjos institucionais e regras de conduta para os membros, o interesse individual de cada Estado não se realizaria. Para as questões de segurança, as motivações se desenharam com clareza quando a tragédia das Guerras Mundiais demonstrou que a cooperação para coibir a violência entre Estados era necessária. Assim, nasceram a Liga das Nações e a ONU. Nesta, os Estados aceitam o mecanismo de segurança coletiva, que autoriza o Conselho de Segurança a tomar medidas (até sanções militares) quando as ameaças à paz se manifestarem contra um deles. O agressor de um é o agressor

50 Ver o meu O interesse e a regra: ensaios sobre o multilateralismo. São Paulo: Paz e Terra, 2008, em que trato das hipóteses sobre o surgimento do multilateralismo e das razões porque os Estados aceitam os constrangimentos quando criam IGMs. 
de todos. De outro lado, as limitações para a atuação do Conselho são conhecidas porque, na Carta, existe uma espécie de reserva de soberania, prescrita no art. 51, que garante aos Estados, em caso de agressão, ações individuais de legítima defesa. ${ }^{51}$ Aliás, a reserva é um dado da vida internacional, justamente porque falta ao sistema internacional um sistema judicial que imponha o cumprimento de normas. Ou seja, cumprir normas é um ato político, soberano e dependerá de processos particulares que induzam o Estado a considerar que é de seu interesse aceitar os constrangimentos jurídicos e de legitimidade da ordem internacional.

Outro dado fundamental do multilateralismo moderno é o feitio democrático dos processos decisórios nas IGMs. Com poucas exceções, como o direito de veto dos membros permanentes do Conselho de Segurança ou o voto ponderado no FMI, prevalece a regra da igualdade dos membros (cada Estado, um voto) e as resoluções são alcançadas por maioria ou consenso, de tal modo que, em tese, as diferenças de poder se diluem. Mesmo os poderosos devem argumentar com a lógica multilateral, ou seja, os interesses individuais para ganharem legitimidade e convencerem os Estados Membros de um organismo qualquer deveriam se multilateralizar: quanto mais se identificar com o interesse da comunidade internacional, maior a possibilidade de que o interesse particular seja aceito multilateralmente. Na medida em que essa identidade entre o particular e o universal se enfraquece, ou seja "esquecida" pelas potências, mais evidente se desenha a crise de legitimidade no sistema internacional, mais precário o destino do multilateralismo. Vai-se retomar o tema adiante.

As múltiplas IGMs e o fato de que persistem mostram que o sistema internacional não é necessariamente ou completamente hobbesiano.

51 Em princípio, mesmo que o Estado invoque a legítima defesa, deve submeter suas ações para aval do Conselho, o que nem sempre acontece, e a norma do artigo 51 foi invocada frequentemente de forma equívoca para justificar atos unilaterais de força. De qualquer forma, se não existe, no sistema internacional, uma entidade que detenha o monopólio do uso da força, o Conselho teria o monopólio para determinar se o uso da força é legítimo ou não, com base nas normas da Carta. 
Há sinais de vida societária no ambiente internacional. A expressão de Hedley Bull é perfeita: o sistema internacional é uma sociedade anárquica. Exatamente por isto, na medida em que se intensificam as relações entre Estados, o escopo das IGMs se amplia em paralelo ao fortalecimento da face social da anarquia: mais intensas as interações entre Estados, maior a necessidade de regulá-las e dar-lhes sentido previsível.

É exatamente esse movimento que amplia a agenda das IGMs. Impressiona o que se espera delas de tal forma que seus objetivos constituiriam os delineamentos para a realização ordenada do que chamaríamos os ideais modernos de uma sociedade internacional justa e estável. A agenda é amplíssima e, entre os objetivos das instituições multilaterais, estariam os de:

a) Promover a paz e garantir a segurança da comunidade internacional; levar adiante o ideal do desarmamento e da não proliferação; facilitar a cooperação na luta contra o terrorismo e os crimes contra a humanidade;

b) Regular o comércio e as relações econômicas entre os Estados de tal forma que haja estabilidade nas transações e os países em desenvolvimento ampliem as suas oportunidades de crescimento;

c) Organizar a luta contra a pobreza e promover o desenvolvimento social, como se estabeleceu nos Objetivos do Milênio;

d) Amparar os refugiados e deslocados e as populações que sofram desastres humanitários;

e) Promover a cooperação para evitar o aquecimento global e prevenir os desastres ambientais;

f) Estabelecer padrões de comportamento para a promoção e defesa dos direitos humanos;

g) Organizar e estimular a cooperação para o combate a epidemias....

A lista não é exaustiva e cobre somente uma parcela do universo das IGMs. Não foram mencionadas, por exemplo, as que se voltam para a 
cooperação mais técnica (em comunicações, como indiquei). Mas, insista-se, por maiores que sejam os desafios, as competências (e esperanças) depositadas nas IGMs correspondem à definição de aspirações que, com diferentes graus de apoio e consistência política, definiram promessas de cooperação e uma concepção de ordem internacional alternativa à que se funda nas relações de poder. Equivaleriam, assim, ao que a comunidade internacional deseja, ao desenho de utopia possível, de uma utopia que teria a legitimidade por ter nascido de processos negociadores de alcance universal.

Como avaliar o que se conseguiu? O resultado não é uniforme. Nos últimos anos, na área de segurança, a história não é linear, com sucessos (Timor) combinados com fracassos (Srebrenica e Ruanda), como a história do Conselho de Segurança demonstra. De outro lado, também sabemos que, em algumas poucas áreas, a cooperação se estruturou e foi mesmo reforçada, ainda que com percalços (como na área de meio ambiente). Assim, as indagações estão abertas: as promessas de cooperação, tão ambiciosas, vão ser cumpridas? Onde haveria mais avanço e onde haveria recuos? Como os diversos temas de cooperação vão interagir?

É evidente que uma resposta cabal para essas questões seria fortemente especulativa, dada a rapidez de movimentos no sistema internacional contemporâneo e a variedade das instituições. Ainda assim, algumas observações são possíveis, a começar da ideia muito frequente e fundada em argumento plausível, de que a globalização induziria à cooperação e ao consequente fortalecimento do multilateralismo. Como as interações entre Estados (e sociedades) se ampliam e se aprofundam, regulá-las é praticamente uma exigência da razão que os Estados perceberiam e transformariam em base para novos modos de relacionamento internacional. A globalização constituiria a base sociológica da vontade multilateral que finalmente se realizaria de maneira plena. Se a hipótese sobre a sociologia do multilateralismo está clara, a sequência do argumento não é nada fácil de equacionar: quais seriam as condições políticas que permitiriam que se realizasse a expansão e aprofundamento 
das normas multilaterais? Quais seriam os fundamentos políticos para que fossem respeitadas?

Para essas indagações, não existe uma resposta ampla e unívoca em função das rapidez e imprevisibilidade das mudanças conjunturais e do fato de que cada passo na regulação da globalização nasce de processos políticos, onde se manifestam contrastes e confrontos de interesses nacionais e variações na dinâmica de poder. Aceitas essas limitações, um caminho possível para pensar o futuro seria rever o que aconteceu no passado recente e o que está acontecendo em nossos dias no universo multilateral.

É difícil, embora não impossível, encontrar razões de otimismo no momento atual da vida internacional. Conflitos se perpetuam sem perspectivas de solução e as Nações Unidas parecem um ator secundário e esquecido naquilo que seria sua função central, propor soluções para paz. É gritante o contraste com o otimismo que reinava quando se criaram as Nações Unidas ou mesmo no princípio dos anos 90, no fim da Guerra Fria. As razões para otimismo nos dois momentos diferem, mas têm um ponto comum. Em ambas as situações, havia uma convergência de interesse das potências (EUA, França, Grã-Bretanha, União Soviética e China) que viam na ONU um instrumento para garantir estabilidade no sistema internacional, regulando a influência que deveriam ter na solução de conflitos localizados. Em São Francisco, as Nações Unidas estabelecem um quadro normativo, pelo qual o Conselho de Segurança assumiria um modelo de autoridade inédito no sistema internacional já que teria poder de intervenção (inclusive armada) para conter ameaças à paz (especialmente invasões territoriais, à feição das que fez o nazi fascismo). Se a Carta da ONU proporciona normas e instrumentos para levar adiante os objetivos da Organização, o ingrediente político dissolveu-se rapidamente com a Guerra Fria, provocando, senão a paralisia da Organização, dificuldades e obstáculos para cumprir o seu papel na área da segurança. Na segunda onda de otimismo, com o fim da Guerra Fria, volta a convergência política, mas não se criam novas instituições. 
Não seriam necessárias porque se imaginava que, superado o conflito ideológico, a ONU estaria preparada para realizar plenamente os ideais de seus fundadores. As normas ganhariam força para que fossem efetivamente executadas. A operação para expulsar o Iraque que invadira o Kuwait desenharia o novo parâmetro para as decisões do Conselho de Segurança. De outro lado, a conclusão da Rodada Uruguai e a criação da OMC revelariam que se estaria concretizando um primeiro passo no sentido de organizar a dimensão comercial da globalização. O GATT, o FMI e o BIRD também superariam as divisões que limitavam o seu alcance durante a Guerra Fria e se reforçariam com a universalidade que o novo padrão de interação entre Estados exigiria. O quadro se completa, nos anos 90, com a série de conferências globais promovidas pela ONU para tratar de temas de interesse universal, como meio ambiente, direitos humanos, direitos da mulher, desenvolvimento social, habitação. Ainda que as resoluções obtidas nas conferências tenham tido ressalvas e a adesão aos resultados tenha encontrado obstáculos, aceitava-se, amplamente, que a ONU passava a servir como foro para que se criassem novos padrões universais de legitimidade, e justamente nos temas novos, que expressariam valores e necessidades universais.

Em suma, a família das instituições multilaterais, centrada em uma ONU prestigiada, não só iria garantir a segurança e estabilidade na ordem internacional como também proporia, com legitimidade e mandatos mais claros, modos novos de organização social. Paz e direitos humanos caminhariam juntos.

A agenda multilateral passa assim a ter três componentes: o primeiro que promete paz e estabilidade, centrado nas atividades do Conselho de Segurança; o segundo que embute promessas de transformação e justiça, especialmente da ordem econômica, e que começa, ainda nos anos 60, como resposta à emergência do Terceiro Mundo, mas que fixa a consciência de que atenuar desigualdades e injustiças é parte intrínseca das instituições multilaterais; o terceiro está definido pelo objetivo de melhorar a própria natureza das relações sociais (direitos humanos) e 
das relações dos homens com a natureza (meio ambiente). Os dois primeiros temas da agenda são territorialistas (preservação da integridade territorial e mudanças nas trocas econômicas entre Estados). O terceiro se abre para temas que afetariam processos nacionais de organização social, gerando assim a possibilidade de uma requalificação da soberania, pois, afinal, o cumprimento ou não das boas normas de respeito aos direitos humanos tem que ver com a relação entre o Estado e o cidadão e é desta relação que passam a falar as resoluções e decisões da ONU.

Como indiquei, nos dias de hoje, qualquer avaliação do progresso da agenda multilateral levaria quase inevitavelmente a um sentimento de frustração. A promessa de paz é abalada pela prolongada e trágica guerra civil na Síria. Os conflitos no Iraque, no Iêmen e na Líbia revelam outras fragilidades da ação do Conselho de Segurança. O mesmo vale para as tímidas reações diante da invasão da Crimeia e dos problemas ucranianos. Não há qualquer sinal de avanço na questão palestina. $\mathrm{O}$ aumento da ameaça terrorista e os riscos da proliferação de armas de destruição de massa não encontram reação adequada. E os sinais de frustração continuam: os progressos modestos em meio ambiente parecem reversíveis; é evidente a fragilidade dos mecanismos de direitos humanos, tão tragicamente expostos com a explosão do drama dos emigrantes que fogem aos conflitos na África e no Oriente Médio; há muito que fazer para que se superem os impasses na Rodada Doha. As propostas mais abrangentes de defesa dos direitos humanos, como a Responsabilidade de Proteger, não se consolidaram e o Tribunal Penal Internacional ainda não obteve a legitimidade e a força que se esperaria de uma corte com responsabilidades tão sensíveis. É como se as três dimensões da agenda multilateral tivessem tocado nos seus limites. A comunidade internacional se acomoda a um nível medíocre de cooperação, que não avança e pode mesmo regredir...

O descompasso entre o desejo de ordem e as realizações da ordem é claríssimo. E, se o futuro for a continuação deste presente, parece que o agravamento da situação internacional não pode ser descartado 
como consequência de divergência crescente entre as grandes potências, especialmente entre EUA, China e Rússia. Em 2014, Walter Russel Mead previa um retorno à geopolítica, com o enfraquecimento natural do multilateralismo, que se reduziria a suas tarefas técnicas. Em contrapartida, ainda que fosse difícil imaginar cenários otimistas, no mesmo número da Foreign Affairs, John Ikenberry argumentava que o modelo liberal dos anos noventa seria suficientemente forte para absorver os choques da realpolitik e não haveria nenhuma potência ou grupo de potências com as condições de rever os fundamentos daquele modelo. ${ }^{52}$ É curioso que, hoje, com Trump, Ikenberry tenha mudado de opinião. Em artigo recente, se indaga se o mundo está assistindo a "demise of the U.S.-led liberal order". Diz que, se está, não é como se imaginava que ia acontecer, já que são os próprios Estados Unidos que estão sabotando a ordem que criaram e conclui: "Across ancient and modern eras, orders built by great powers have come and gone - but they have usually ended in murder, not suicide". ${ }^{33}$ Especular sobre as consequências específicas da "demise" da ordem liberal exige refletir sobre qual seria o alcance de deterioração que o multilateralismo vai sofrer nos próximos anos. Ainda que as perspectivas sejam pessimistas, é possível admitir que, mesmo com o radicalismo de um Trump, uma mudança abrangente da ordem como a conhecemos não deverá acontecer nos próximos trinta anos. Ou seja: a geopolítica não destruirá o multilateralismo e a ONU ainda estará atuante em 2050 (essencialmente porque os Estados ainda estarão vivos). Entretanto, é improvável que, até lá, as promessas do multilateralismo estejam plenamente cumpridas. Provavelmente soluções intermediárias vão ocorrer e a dificuldade será antecipar como se combinarão os ingredientes de realismo e de liberalismo nos próximos anos. Nos dias de hoje, vale observar que, a despeito dos motivos para

\footnotetext{
$52 \mathrm{O}$ debate entre Mead ("The return of geopolitics") e Ikenberry ("The illusion of geopolitcs") está no número de junho de 2014 da revista Foreign Affairs.

53 J. Ikenberry, "The Plot against American Foreign Policy", Foreign Affairs, maio/ junho 2017, pág. 2.
} 
frustração, a maquinaria multilateral não se paralisou. O Conselho de Segurança se reúne regularmente e toma decisões, algumas em áreas problemáticas como no levantamento das armas químicas na Síria (já no suposto ataque recente, ficou paralisado); as negociações sobre meio ambiente avançaram modestamente e o mesmo vale para o comércio; os órgãos de direitos humanos funcionam regularmente embora com influência modesta para influir diretamente quando violações ocorrem persistente e amplamente, etc. Não vivemos um momento dinâmico e criativo no universo multilateral, mas ainda longe do caos.

Como determinar as forças que definirão o futuro do multilateralismo? Não tenho, evidentemente, nenhuma projeção clara e segura, mas apenas algumas observações não muito sistemáticas:

a) As instituições multilaterais foram criadas pelas potências hegemônicas. Os Estados Unidos estão na origem da ONU, do GATT, do TPI, etc. e sempre foram decisivos para dar-lhes força ou desprestigiá-los. Sabemos que os Estados Unidos não têm sido o mais fiel dos multilateralistas e, de várias formas, afastou-se de seu impulso inicial para apoiar instituições multilaterais. O exemplo mais curioso é o fato de que são o único país que não ratificou a convenção para proteção dos direitos da criança, moldada aliás por leis americanas. ${ }^{54}$ Neste sentido, algumas posições de Trump não são propriamente novidade e repetem, com excessos quase caricaturais, atitudes antimultilaterais do repertório diplomático dos EUA (lembremos de John Bolton, representante permanente na ONU, ao tempo do segundo Bush). De qualquer modo, pelo peso de poder que tem, o comportamento dos EUA, às vezes errático, é o começo necessário para as reflexões sobre o futuro. Fica a observação: por mais antimultilateralista que tenha sido, inclusive se retirando de IGMs, os EUA afetaram, mas nunca decisivamente mesmo aquelas objeto de ataque e crítica, como a UNESCO e a OIT. O problema maior estaria na área de segurança em vista do trunfo negativo dos EUA (e

${ }^{54}$ Porém o afastamento mais trágico foram as prisões clandestinas e o uso de tortura. 
dos membros permanentes do Conselho de Segurança) que é o poder de veto. Este, sim, pode levar à paralisia de uma agência fundamental para a ordem internacional.

b) A promoção americana do multilateralismo não foi um exercício solitário nem poderia sê-lo. É da própria natureza do multilateralismo a criação coletiva que envolve, normalmente, as potências (como no caso da Liga e da ONU), mas não só. Especialmente quando são lançadas, as IGMs devem contar com forte legitimidade, inclusive para transformar o que seria um agregado limitado de interesses em um objetivo amplo da comunidade internacional e, assim, convencer os Estados a aceitar os objetivos e regras da instituição. As IGMs podem nascer para servir aos interesses de seus inspiradores, mas deve ultrapassá-los e é isto que lhes garante a legitimidade. As IGMs não existem em vácuo de poder. Dependem de conjunturas políticas favoráveis para cumprir plenamente o seu papel. Não seriam, porém, variáveis puramente dependentes.

c) De fato, uma vez criadas, as instituições tendem a ganhar uma medida de autonomia diante de seus criadores e, em algumas circunstâncias, abrem as portas para rebeliões contra eles. ${ }^{55}$ Porém, sem o apoio das potências, trabalham com limitações evidentes. Podem ser referência de legitimidade mas perdem em eficácia e autoridade.

d) Temos, hoje, um estoque de instituições, normas, regras, regimes que cobrem praticamente todos os aspectos da vida internacional. A força das instituições supõe que se realizem umas tantas condições: o respeito às suas normas e decisões, a convergência da vontade das potências (e dos que pesam nos temas específicos), a legitimidade de seus propósitos e a eficiência dos serviços que prestam. São evidentemente imensas as dificuldades para realizar tais condições em um ambiente político diversificado, marcado por desigualdades, e conflitivo em vários planos.

55 O caso clássico é a história da Assembleia Geral da ONU que, no início, foi simplesmente uma avalista de interesses americanos e, depois da entrada das ex-colônias, multiplicou resoluções que criticavam ações políticas dos EUA. 
Assim, há hoje obstáculos para a reconfirmação da própria relevância do multilateralismo. Em primeiro lugar, obstáculos intrínsecos, que se mostram no processo de aplicar regras estabelecidas ou construir novas, como nos exemplos do desacordo em relação: 1) à natureza das ameaças à paz, ponto de partida para qualquer ação do Conselho de Segurança; 2) a maneiras de reformar o Conselho, cuja composição está em descompasso com as transformações do sistema internacional; 3) ao alcance do combate às violações maciças de direitos humanos; 4) às formas de superar os obstáculos à criação de um regime "forte" em matéria de desenvolvimento sustentável, etc... ${ }^{56}$ Outra dificuldade nasce do fato de as resoluções e normas que formam a base do processo decisório apoiarem-se frequentemente em consensos frágeis, como no caso da Responsabilidade de Proteger. ${ }^{57}$

Parte dessas dificuldades se explica pelo que seriam os obstáculos extrínsecos, aqueles ligados à natureza da distribuição de poder no sistema internacional. Não existe um Estado hegemônico (o momento unipolar terminou) nem uma coalização hegemônica, que esteja disposta a (ou tenha condições de) defender e bancar a causa multilateral. Os emergentes e os países em desenvolvimento ainda não encontraram alianças consistentes que pudessem constituir, globalmente, alternativas às potências. As diferenças, acima apontadas, revelam divergências estratégicas na forma encarar os problemas globais, paralisando os mecanismos multilaterais. Perde-se, assim, a virtude essencial do multilateralismo que é o acomodar interesses entre Estados diferentes pelos interesses e pelo poder. As dificuldades crescem na medida em que se cria um ciclo vicioso: os interesses nacionais e limitados se manifestam, entram em

\footnotetext{
56 As alternativas regionais, e o exemplo mais acabado seria a UE, também sofrem com impasses e dificuldades.

57 Mesmo quando existem consensos fortes, como no caso das resoluções que pedem que Israel se retire dos territórios ocupados ou das inúmeras conclamações para que se avance no sentido do desarmamento nuclear, não há garantia de que a norma internacional se imponha.
} 
conflito, o campo (multilateral) de negociação não é considerado como espaço próprio para acomodá-los, e o passo seguinte é esquecer as IGMs e buscar rotas alternativas para lidar com os desacordos e conflitos. Não é o caso de discutir porquê do ressurgimento do sacro egoísmo no mundo das nações. Ficamos com as consequências para o mundo multilateral.

A tendência persistirá? Estamos diante da perspectiva da falência do sistema multilateral? Só restariam as instituições técnicas? Como indiquei, não creio que isto vá ocorrer e um dos elementos a considerar no desenho das variáveis que definem o futuro é a distribuição de poder no sistema internacional.

Há várias alternativas para caracterizar o sistema contemporâneo, que apresenta uma combinação de tendências: um unipolarismo evanescente (mas que não dilui a capacidade americana de influenciar toda a agenda internacional, com capacidade para bloquear avanços, mais do que promovê-los) que pode se combinar com a perspectiva de G2, China e EUA, que ressuscitariam um bipolarismo ao feitio da Guerra Fria com a hipótese de momentos de détente entre os dois, desde que consigam estabilizar as inúmeras áreas de divergência que existem atualmente. ${ }^{58}$ Cenários alternativos exploram a possibilidade de arranjos multipolares, ora com as potências estabelecidas, ora com a presença dos chamados emergentes. Talvez uma das melhores caracterizações do momento seja de Joseph Nye, ao dizer que o mundo se parecia com um jogo de xadrez em três dimensões: o poder militar estaria altamente concentrado nos EUA; o econômico distribuído de modo multipolar entre EUA, União Europeia, Japão e os BRICs; e o poder sobre os temas universais, como mudança climática, combate ao terrorismo e ao crime organizado, é alta-

\footnotetext{
58 Como no caso do TNP, divergências profundas não excluem a possibilidade de arranjos estimulados pelo interesse que nasce pelo próprio interesse das potências em se diferenciar dos demais Estados e criar condições especiais para preservar as vantagens que possuem.
} 
mente difuso. ${ }^{59}$ Ou seja, o mundo não é unipolar, multipolar ou caótico. Combina as três faces ao mesmo tempo...

A diversidade de faces do sistema de poder não traria, em si, incompatibilidade estrutural com o avanço do multilateralismo. Afinal, a ONU foi criada em momento unipolar, já que, ao fim da II Guerra, as vantagens de poder dos EUA eram incontrastáveis; a Liga em fase de reordenamento multipolar; e, mesmo durante a Guerra Fria, se o Conselho de Segurança estava paralisado, os foros universais não estavam e promoveram (ou ajudaram a promover) a descolonização, as propostas de nova ordem econômica, as convenções de direitos humanos, as normas de direito do mar, etc., além de servir aos interesses das potências, como na negociação conduzida pelos EUA e pela URSS para elaborar o Tratado de Não Proliferação. O problema seria, então, como assinalei, a ligação de exercício hegemônico com o multilateralismo. Isto não ocorre ou ocorre precariamente. Os EUA teriam capacidade de projetar poder militar, mas não de legitimá-lo ou fazê-lo com a eficiência necessária para lidar com as situações complexas das guerras modernas (com forte componente de ingredientes nacionais e transnacionais). Faltariam aos EUA a disposição de buscar a legitimidade do Conselho e a abertura para alianças que alargassem a eficiência de intervenções. É difícil imaginar progressos na agenda ambiental ou comercial sem ampla participação das potências (que não conseguem mais impor suas vontades) e dos emergentes, que têm peso alto em negociações específicas, mas não para impor alternativas ou para formulá-las com vigor político. ${ }^{60}$ As ONGs são decisivas na agenda dos direitos humanos e meio ambiente e influenciam decisões com base na pressão pública sobre os agentes governamentais. Têm

59 Ver Joseph S. Nye, American Power in 21st century, disponível em https://www. hks.harvard.edu/news-events/news/news-archive/american-power-21st-century

60 Também aberto está o tema da capacidade dos emergentes de atuar em conjunto, já que são muitas as divergências entre eles (veja-se a resistência da China à entrada da Índia como membro permanente do Conselho de Segurança). 
um papel na construção da ordem, mas limitado pela temática e pela capacidade efetiva de mudar o comportamento dos Estados.

Essa caracterização do cenário internacional, ainda que imperfeita, pode nos ajudar a extrair algumas observações para o futuro do multilateralismo.

Para superar o pessimismo a que a situação presente induz, haveria que imaginar dois movimentos: uma reaproximação entre as potências (que superariam as suas disputas particulares por algum grand design) e a aproximação entre elas e os emergentes, que ofereceriam as suas perspectivas novas para a recomposição da plena legitimidade e eficácia das IGMs. Haveria alguma possibilidade de que esse cenário prevalecesse?

Parece fora do horizonte um novo ímpeto para o multilateralismo baseado na reconstituição da hegemonia organizada pelas potências tradicionais. Existe uma acumulação de conflitos (de visão e de interesse) entre elas e que não devem arrefecer. Outro elemento: não existe nenhum impulso ideológico, com ingredientes utópicos, como ocorreu em São Francisco em 1945, para motivar as potências. As narrativas internacionais se fragmentaram. A indiferença diante da necessidade de uma reforma da ONU ao fim da Guerra Fria é sintoma de que há uma espécie de esgotamento das grandes ideias, as motivações utópicas estão descartadas.

De outro lado, é razoável admitir que a soma dos conflitos localizados entre as potências não levará a uma confrontação militar. É claro que, na medida em que os conflitos permanecessem abertos e se tornassem rígidos, as consequências para o multilateralismo seriam desastrosas, sofrendo em primeiro lugar os instrumentos de segurança coletiva. $\mathrm{O}$ mais provável é que prevaleça a multipolaridade e, como na clássica, regida por alguma forma de balança de poder. ${ }^{61}$

$61 \mathrm{O}$ modelo de multipolaridade, como o desenvolvido por Kaplan para o mundo europeu do século XIX, ensina pouco sobre o que está ocorrendo hoje. As regras se aplicariam se houvesse maior paridade entre as potências e se, para conter a expansionista, as outras se coligassem. Ora, a hipótese mais próxima a esse cenário seria uma atitude 
Há elementos que colocam limites à difusão do conflito, e o primeiro é o contraponto de arsenais nucleares, que limitaram os conflitos na Guerra Fria e continuarão a fazê-lo agora. Outro fator é a profundidade das ligações comerciais e financeiras, especialmente entre China e os Estados Unidos, os candidatos naturais, nas análises estruturalistas, a um confronto por hegemonia. $O$ terceiro elemento é a ausência de ideologia expansionista, como na Guerra Fria, supondo-se que os conflitos estratégicos sejam mais negociáveis do que os que contrapõem ideias e convicções. ${ }^{62}$

Ficamos assim com a hipótese de que não há perspectiva de avanço do multilateralismo, mas também a de que as instituições continuariam, provavelmente com funções diminuídas, embora seja impensável eliminar a agenda estabelecida, especialmente em torno de temas globais. No campo da segurança, além de presença nos conflitos periféricos, as instituições multilaterais poderiam vir a atuar no relacionamento as potências, como ocorria na Guerra Fria. Não há uma tendência a que necessariamente a soma de disputas de converta em conflito global e militar e o reverso também é verdadeiro. Não existe nenhuma tendência visível que mostre que a situação presente alimentaria uma volta ao prestígio e força das IGMs.

\footnotetext{
claramente expansionista da China que levasse a uma coalização dos EUA com a Rússia e a Europa. Mas, hoje, tanto no caso da Rússia quanto da China, as atividades para alargar influência se limitam ao regional e as reações são também limitadas. Provavelmente induziriam a movimentos de contenção, mas, como o cenário não é mais limitado geograficamente, como na Europa, as reações seriam limitadas, como, aliás, vimos no caso da Crimeia e mesmo da Ucrânia. A suposição é de que não existiriam, nesses casos, para os EUA e para a Europa, interesses vitais ameaçados imediatamente. Ver Kaplan, M. "Variants on Six Models of the International System" in James N. Rosenau, (editor). International politics and foreign policy; $A$ reader in research and theory. Nova Iorque: Free Press of Glencoe, Inc., 1961

62 Observe-se a persistência do conflito no Oriente Médio que mistura ingredientes estratégicos e ideológicos e que esteve presente de várias formas na agenda das potências. Compare-se os riscos que embutia ao tempo da Guerra Fria com o que ocorre hoje. As potências estão lá, mas de outra forma, com outro tipo de confrontação. Um segundo problema são os choques de visões de civilização que acabam por afetar, por exemplo, as populações muçulmanas na Europa, mas que não levam a conflitos entre Estados, salvo no Oriente Médio.
} 
Se a conclusão é de que não temos elementos para dizer que o futuro será pior ou melhor que o presente, é preciso, contudo, atentar para aqueles fatores que podem influenciar negativa ou positivamente $o$ curso dos próximos movimentos na ordem internacional. Infelizmente, é mais fácil imaginar os fatores que exacerbam as tendências negativas, ao menos a curto prazo. Tomemos uns poucos exemplos: a tolerância às guerras regionais prolongadas, com múltiplos atores e sem processos definidos de negociação. A guerra na Síria é o triste exemplo de como as diferenças entre as potências podem se enrijecer, obliterando o papel dos organismos multilaterais, e criando fontes duradoras de fricção que anulam a possibilidade de que a multipolaridade seja um fator de distensão, que aproveitasse a multiplicidade de visões que poderia ensejar. A multipolaridade do século XXI lida com conflitos complexos, mas que não afetam diretamente as margens de segurança das potências e assim, não estimulam mecanismos de solução de conflitos, menos ainda os multilaterais. $\mathrm{Na}$ ordem que vivemos, expandem-se os conflitos e suas consequências trágicas, mas aumenta paralelamente a tolerância ao conflito e às tragédias humanitárias. ${ }^{63} \mathrm{Na}$ medida em que as potências não são afetadas em seus interesses vitais e imediatos, aceita-se a "inevitabilidade" de um sistema hobbesiano e os conflitos passam a ser essencialmente objeto de jogos estratégicos, uns mais relevantes do que outros, nenhum vital. ${ }^{64}$

Esse equilíbrio instável pode sofrer abalos, que enfraqueceriam o recurso ao multilateralismo. $\mathrm{O}$ primeiro corresponderia a uma exacerbação da tendência acima descrita, com o agravamento em áreas mais "próximas" estrategicamente aos interesses das potências. O exemplo

63 O efeito $\mathrm{CNN}$, que desperta setores sociais para tragédias humanitárias, é real, mas pode se contrapor, infelizmente, ao fato de que a persistência de conflitos, como o da Síria, entorpece a vontade que deveriam ter os Estados de buscar soluções para a violência da guerra. Os interesses estratégicos prevalecem sobre os humanitários.

${ }^{64}$ Algum interesse afeta, até de prestígio ou de mudança de equilíbrio estratégico. A dificuldade é imaginar hoje, salvo de forma muito especulativa, o momento em que os afetados sejam definidos como "vitais". 
mais evidente é a situação da Coreia do Norte, essencialmente porque não se sabe o grau de racionalidade que comandaria a ação de seus dirigentes. Ou seja: ainda que contrarie as aspirações, normas e decisões do Conselho de Segurança, o problema vai além do fato de que detenha armas nucleares. Existe a possibilidade de um manejo contido e "racional" das armas nucleares, como argumentam as potências nucleares que se negam a movimentos mais amplos e completos de desarmamento. A questão é até que ponto Kim Jon-un será racional e contido no uso das armas nucleares. Não se sabe de quantas armas nucleares os norte-coreanos dispõem e muito menos se articularam uma doutrina de uso. Exatamente por isto, as tensões prolongadas na região introduzem um perigoso elemento de imprevisibilidade na multipolaridade.

Se a questão anterior lida com conflitos complexos, mas que, em última instância, podem ser trabalhados diplomaticamente, outro abalo adviria da possibilidade de mudanças de padrão da legitimidade. Durante a Guerra Fria, a força de legitimidade das instituições multilaterais, especialmente a das Nações Unidas, foi afetada por violações frequentes da Carta. Porém, o tributo ao multilateralismo continuava mesmo por aqueles que despeitavam suas regras, com base em "legitimidades alternativas" (que justificaram a intervenção soviética na Hungria e na Polônia ou a dos EUA no Vietnam ou na República Dominicana). A suposição é de que a defesa do mundo livre ou da construção do socialismo superava os constrangimentos da autodeterminação e permitia as intervenções. Agora, o desafio à legitimidade multilateral tem outro alcance e riscos evidentes. A tendência marcada pela volta de um nacionalismo que se fecha para o mundo ("meu país primeiro"), como o de Trump, de Le Pen, do que levou ao Brexit e às barreiras à entrada de refugiados na Europa, ao protecionismo, traz consequências graves para o multilateralismo. O nacionalismo não é em si mesmo incompatível com a presença nas instituições multilaterais, desde que a defesa de interesses nacionais não signifique a hipótese de responsabilizar as IGMs pela dificuldade de realizá-lo. Essa atitude ataca o cerne do processo multilateral, que 
parte do princípio de que a projeção de interesses na arena internacional envolve negociação e o resultado, raramente ou quase nunca (mesmo para as potências) é igual ao "desejo" inicial. Os modelos de argumento são contraditórios. Os que aceitam que a comunidade internacional cria legitimidade diriam: projeto o meu interesse mas admito que, para realizá-lo, devo levar em conta o interesse dos outros e da comunidade internacional; os outros diriam: projeto o meu desejo que se realizará em qualquer circunstância, mesmo contra o interesse dos outros e os da comunidade internacional. É evidente que o deslocamento do eixo da legitimidade para que se sustente exclusivamente no interesse nacionalmente definido significará desprestígio e enfraquecimento crescentes do multilateralismo. Daí talvez a maior perda que ocorre com o Brexit e o enfraquecimento da União Europeia, que, além de funcionar como um fator de equilíbrio no jogo multipolar, valia como símbolo de que mais multilateralismo significaria mais poder, mais bem-estar para as populações, mais prestígio internacional.

A nota é pessimista e natural para quem escreve nos dias de hoje e admite que é difícil enxergar sinais positivos para futuro do multilateralismo. Mas, vale insistir em três pontos. O primeiro, de natureza estrutural, lembra que a globalização está suficientemente enraizada para que o multilateralismo técnico se mantenha e até mesmo ganhe novos contornos. Lembremos as teorias funcionalistas do início do século XX, que afiançavam que o aumento de conexões (comércio, comunicação, etc.) seria um dos fundamentos da paz. Provavelmente, a teoria exige ressalvas, mas as trocas financeiras e comerciais entre as potências são um fator que inibe conflitos e obriga a manter níveis altos de cooperação em áreas variadas. Outro dado é a inércia que fará com que o mundo multilateral se preserve como tal e mesmo se expanda nos próximos anos.

O segundo elemento dependerá de situações conjunturais em que ameaças vistas como comuns levem a novos consensos no Conselho de Segurança. Se a Coreia do Norte pode desencadear conflitos, exatamente pela imprevisibilidade do comportamento de seus dirigentes, pode 
também exigir cooperação mais cerrada entre as potências para evitar consequências trágicas se armas nucleares fossem usadas. É evidente que não é a melhor rota para fortalecer o multilateralismo, mas não pode ser descartada.

Finalmente, há questões internacionais que, pela própria natureza, são multilaterais, mobilizam a opinião pública (ONGs), como meio ambiente e direitos humanos. Os temas vão continuar abertos e são permanentes. Apesar dos estragos que o governo Trump tenta fazer na política ambiental norte-americana, com evidentes consequências para a negociação multilateral, o curso das mudanças climáticas vai ser sentido e exigir ação internacional. O mesmo vale para o impacto que têm as violações de direitos humanos na opinião pública internacional e que, ainda que de forma seletiva, acabam por afetar as decisões dos Estados.

Em suma, a multipolaridade, mesmo que se abra para os emergentes, não leva necessariamente à criação de relações benignas entre os Estados. Certamente é melhor que o unipolarismo ou o bipolarismo. Mas, a que vemos se desenhar agora, com a prevalência militar dos Estados Unidos, a dispersão do poder econômico, a complexidade dos conflitos, é um novo tipo de multipolaridade para o qual os modelos do século XIX não oferecem todas as chaves. Uma das diferenças é justamente a existência de instituições multilaterais que, ainda que tenham perdido prestígio, continuam a ofertar soluções racionais e espaços de negociação para recompor uma ordem internacional que parece primar pela incapacidade de gerar soluções para problemas que só se agravam. A referência a alternativas continua como parâmetro crítico para o comportamento dos Estados. O que parece perdido, sim, é o que restava de utopia, de vontade de modelar o futuro, de imaginar futuros de paz perpétua, utopia que está na origem histórica do multilateralismo. Mas, não se perdeu a consciência de que há alternativas à política de poder. 


\section{Nota sobre o Brasil e o futuro do multilateralismo}

A fragilização do multilateralismo não é favorável à política externa brasileira, por várias razões. A projeção internacional do Brasil é essencialmente diplomática. Não participamos do jogo internacional com recursos de "poder duro"; não somos uma potência econômica; não promovemos ideologias ou modelos de organização social. Ora, como o universo multilateral é tecido por processos diplomáticos, é fácil entender a nossa adesão histórica ao multilateralismo.

Através das instituições multilaterais, exercemos, em primeiro lugar, a possibilidade de participar das questões globais e, daí, a ambição de um assento permanente no Conselho de Segurança. Em segundo lugar, para um país que não tem "excedentes de poder", o multilateralismo, quando mais avança, mais fortalece as alternativas que o direito oferece às políticas de poder. Além disto, é no universo multilateral que se abre o espaço para a criação diplomática e, em nosso caso, isto vale para iniciativas na ONU, como a Zona de Paz para o Atlântico Sul, a Responsabilidade ao Proteger e em diversas iniciativas nas conferências de revisão do Tratado de Não Proliferação; e, na região, a mais conhecida seria o MERCOSUL. Promovemos encontros de cúpula entre a América do Sul e os países africanos e árabes, porque, ao pertencermos ao mundo ocidental e ao mundo em desenvolvimento, abrem-se para nós possibilidades de aproximar posições antagônicas em várias conferências internacionais, como direitos humanos e meio ambiente. Finalmente, a facilidade de participar do universo multilateral nasce do fato de que as posições brasileiras são afins aos padrões da legitimidade internacional. Em suma, as IGMs são, por definição, um campo de oportunidades e não de ameaças. Eventualmente, podem exigir atitudes defensivas, mas é o espaço que se abre para a projeção internacional do Brasil. Se essa caracterização da atitude brasileira em relação ao multilateralismo é correta, a pergunta que decorre naturalmente é o que a diplomacia do país pode/deve fazer diante do quadro que se desenha hoje. 
A resposta mais geral e mais evidente seria a de que um objetivo central da política externa seria defender e promover o próprio multilateralismo. Ou seja, ir além de usar as instituições multilaterais, mas lutar para que não sejam diminuídas ou substituídas nas funções para as quais foram criadas. Desta forma, a diplomacia seria fiel à sua história, não inovaria, simplesmente teria que se adaptar aos desafios que a conjuntura oferece. Não alteraria conceitos fundamentais mas o estilo e a atitude para apresentá-las. Neste ponto, a indagação prosseguiria: como fazer para ir além da defesa em tese do multilateralismo, como torná-la efetiva em um cenário em que provavelmente a ordem internacional se baseará em um sistema de poder multipolar? Quais seriam os caminhos políticos que dariam efetividade ao esforço de reforçar o multilateralismo?65

Há dois caminhos possíveis, o das alianças globais e o das alianças variáveis. Ambos devem partir da observação de que a multipolaridade contemporânea é mais complexa do que a clássica. Nesta, as alianças se formavam para conter o expansionismo de Estados com ambição hegemônica e o cerne das disputas era territorial. As alianças variavam, mas tinham objetivos claros.

Agora, a hipótese de se repetir, na defesa do multilateralismo, um comportamento "clássico" é remota, por uma razão muito simples. Não haveria um polo que encarnasse o "inimigo do multilateralismo", talvez até o surgimento de Trump. Mas, faria sentido uma aliança contra Trump que contasse com outros polos que fossem uniformemente multilateralistas? É improvável porque a defesa do multilateralismo varia entre as potências. A França e a Grã-Bretanha se aliam com os EUA em matéria de desarmamento, mas se afastam nas questões de direitos humanos e meio ambiente. Não há uniformidade de critérios nos temas de não

65 Antes de prosseguir, é necessário sublinhar que, a meu ver, o enfraquecimento do multilateralismo não significa que a agenda seja esquecida. $O$ campo multilateral continua e, para o Brasil, continuará como instrumento privilegiado de projeção diplomática. 
proliferação ou na reforma do Conselho de Segurança. Uma alternativa seria articular um grupo de países que, com comportamentos afins em relação ao multilateralismo, se tornasse, pelo peso, um novo polo no jogo de poder, só que voltado à valorização do multilateralismo. De uma certa maneira, foi o que se tentou com o Fórum de Diálogo Índia, Brasil e África do Sul (IBAS) e, depois, o BRICS. Neste caso, ainda que o grupo tenha tido sucesso especialmente na área financeira, em outros, há diferenças marcantes que limitam a sua capacidade de atuação, como na reforma do Conselho de Segurança.

Assim, a escolha do caminho de alianças variáveis é o cenário mais provável induzido pela própria natureza do jogo multipolar. Para o Brasil, e talvez outros emergentes, há duas maneiras de atuar. A primeira é buscar alianças específicas, que vão variar em função dos temas e, de uma certa maneira, essa atitude já é a adotada pela diplomacia brasileira. Teria possivelmente que ser reforçada e agregar uma dimensão adicional, que é a de incorporar os que relutam em buscar os caminhos multilaterais. Não é nada fácil, mas é o desafio corrente. O segundo caminho seria intervir diretamente em conflitos que envolvam as potências. O exemplo emblemático é a tentativa de intervir na controvérsia sobre o desenvolvimento nuclear do Irã. Não foi bem-sucedida, mas isto não retira legitimidade da ação, nem exclui possibilidade de que se volte a tentá-la no futuro, talvez com mandato mais claro e menos ambição. Porém, na região, o Brasil tem um papel a desempenhar, sobretudo para mediar conflitos e evitar que haja interferências externas nas situações nacionais.

A vocação multilateral é parte essencial do modo brasileiro de estar no mundo. Por isto, uma das questões essenciais da diplomacia brasileira é definir estratégias que contribuam para que o multilateralismo mantenha prestígio e efetividade. As opções vão depender de como evoluirá o sistema internacional e as possibilidades de avançar na ampla agenda multilateral que, quer se queira quer não, mesmo combalida, ainda é necessária e referência fundamental para a legitimidade internacional. 